\title{
Numerical analysis of costal cartilage warping after laser modification
}

\author{
Allen Foulad*, Cyrus Manuel, Jinwan Kim, Brian JF Wong \\ From 2nd Scientific Meeting of the Head and Neck Optical Diagnostics Society \\ San Francisco, CA, USA. 23-24 January 2010
}

Grafts obtained from peripheral regions of costal cartilage have an inherent tendency to warp over time. Laser irradiation provides a potential method to control the warping process, thus yielding stable grafts for facial reconstructive surgery. In our current study, we propose a simple and well-fitting model that numerically describes the degree of warping of laser irradiated costal cartilage grafts. Using an Nd:YAG laser (lambda $=1.32$ $\mu \mathrm{m})$ at various exposure settings, grafts harvested from the peripheral regions of porcine costal cartilage were irradiated. The resulting graft geometry was fitted to a curve using a quadratic regression model. The coefficient of determination demonstrated a very strong fit for all grafts modeled. A quadratic regression is simple to perform and results in a single numerical value that appropriately describes the degree of cartilage warping. Our proposed model is valuable in assessing the effect of laser irradiation on the warping process of costal cartilage.

- Convenient online submission

- Thorough peer review

- No space constraints or color figure charges

- Immediate publication on acceptance

- Inclusion in PubMed, CAS, Scopus and Google Scholar

- Research which is freely available for redistribution 